\title{
Transient angular stability on medium voltage distribution systems with distributed generation
}

\section{Estabilidad angular transitoria en sistemas de distribución de media tensión con generación distribuida}

\author{
CISNEROS-VILLALOBOS, Luis †', VERA-DIMAS, José Gerardo’', AGUILAR-MARIN, Jorge Luis*’ \\ and VERGARA-VÁZQUEZ, Julio Cesar"
}

'Universidad Autónoma del Estado de Morelos, Faculty of Chemical Sciences and Engineering. Cuernavaca, Morelos, Mexico.

"Centro Nacional de Investigación y Desarrollo Tecnológico, Mechanical Engineering Department, Cuernavaca, Morelos, Mexico.

ID $1^{\text {st }}$ Author: Luis, Cisneros-Villalobos / ORC ID: 0000-0002-9409-1374, Researcher ID: ABD-4724-2020, CVU CONACYT ID: 82259

ID $1^{\text {st }}$ Co-author: José Gerardo, Vera-Dimas / ORC ID: 0000-0002-3880-3568, Researcher ID: AAC-4923-2021

ID $2^{\text {nd }}$ Co-author: Jorge Luis, Aguilar-Marin / ORC ID: 0000-0002-0235-6946, Researcher ID: ABD-4533-2020, CVU CONACYT ID: 1010823

ID $3^{\text {rd }}$ Co-author: Julio Cesar, Vergara-Vázquez / ORC ID: 0000-0003-1524-7914, Researcher ID: ABD-5487-2020

\begin{abstract}
The dynamic behaviour of a $32 \mathrm{MW}$ gas-turbine generating unit, connected to the $23 \mathrm{kV}$ main busbar of a substation, is analysed in this article. The study is focused on the representative faults occurring in an electrical system and allows the determination of the maximum times in with a fault must be delivered to maintain the stability of generator. A three-phase power network is modelled with the Alternative Transients Program (ATP). Simulation results are reported and analysed for typical variables of interest such as machine rotor angle, frequency, and power. According to the study results, machine stability is greatly affected by three-phase faults, as compared to the dynamic behaviour under singlephase faults. The analysis carried out is useful to improve and maintain the security of operation of the electrical grid and in aligned to the current regulations and recent reforms of the Mexican electric sector. The fact that the performed study was usually not mandatory but has been pending since the commissioning of distributed generation plants in the Central Mexican Region is emphasized.
\end{abstract}

Distributed generation, Distribution sub-station, Medium voltage, Transient stability

\begin{abstract}
Resumen
En este artículo se analiza el comportamiento dinámico de una unidad generadora de turbina de gas de $32 \mathrm{MW}$, conectada a la barra principal de $23 \mathrm{kV}$ de una subestación. El estudio se centra en las fallas representativas que ocurren en un sistema eléctrico y permite determinar los tiempos máximos en los que se debe entregar una falla para mantener la estabilidad del generador. Una red de energía trifásica se modela con el software Alternative Transients Program (ATP). Los resultados de la simulación se informan y analizan para las variables típicas de interés, como el ángulo, la frecuencia y la potencia del rotor de la máquina. Según los resultados del estudio, la estabilidad de la máquina se ve muy afectada por fallas trifásicas, en comparación con el comportamiento dinámico en fallas monofásicas. El análisis realizado es útil para mejorar y mantener la seguridad de operación de la red eléctrica y está alineado con la normativa vigente y las recientes reformas del sector eléctrico mexicano. Se destaca el hecho de que el estudio realizado generalmente no era obligatorio, pero se encuentra pendiente desde la puesta en servicio de plantas de generación distribuida en la Región Centro México.
\end{abstract}

Generación distribuida, Subestación de distribución, Media tensión, Estabilidad transitoria

Citation: CISNEROS-VILLALOBOS, Luis, VERA-DIMAS, José Gerardo, AGUILAR-MARIN, Jorge Luis and VERGARA-VÁZQUEZ, Julio Cesar. Transient angular stability on medium voltage distribution systems with distributed generation. Journal of Scientific and Technical Applications. 2021. 7-19:1-8.

\footnotetext{
* Correspondence to Author (Email: jorge.aguilar.itt@gmail.com)

$\dagger$ Researcher contributing as first author.
} 


\section{Introduction}

With the entry of the Wholesale Electricity Market in Mexico, where the short-term market was put into operation in January 2016 and its current regulations (CRE, 2016), a new diversity of studies of the electricity networks is required. The deregulation of the electricity markets has allowed the generation capacity to be increased not only in the power grid but also in the distribution networks. This has created an interest on the part of energy trading companies to interconnect with public electricity networks (Rosales et al 2000) complying with various technical requirements.

An option to meet the growing demand for electricity from public networks considers adding sources of generation as close as possible to charging centers at certain points in the network (Paine, 2002). These energy sources are known as distributed generation and can use renewable energy or non-renewable energy. By properly selecting the insertion points of the generation, it is possible to recover a certain amount of the transmission and transformation capacity of the electricity grid and thus obtain a better quality of the electrical energy used because there is better voltage support, harmonic components and energy losses are reduced (Shilling, 1997). Moreover, by recovering the capacity of the system there is more time to budget, plan, schedule and conclude projects that alleviate or strengthen the electricity network (Dommen \& Kohler, 1995).

The design and planning of electrical networks involve topics as short circuit, power flow, protection coordination and some others such as electromagnetic transients, insulation coordination, motor starting and electric arc studies (IEEE, 1997). Recently the study of transient stability has considered new conditions about the operation of a grid that may represent a risk in the electric system (CRE, 2016). Transient stability is important because it relates directly to energy sources that are included in an electrical system (Dunki \& Davis, 1994).

Historically, the study of transient stability was handled by specialized personnel, this study was developed specifically when generators connected to the backbone power networks.
In Mexico, the public distribution network includes the generation of electricity with various technologies and one of them is through the use of conventional synchronous machines. It must be taken on account that the disturbances due to short circuits in the aerial distribution networks are frequent (CFE, 2017), these disturbances cause a dynamic behavior between the generators and the electrical network that largely determines the successful operation of the electrical system. Thus, in this document, the classical stability of a synchronous generator connected to a public medium voltage network is evaluated due to disturbances caused by short circuits. (Dunki \& Davis, 1994) presents some reasons why the studies of transient stability were not so frequent.

Currently, aspects such as operational flexibility, inclusion of new processes in the medium voltage networks and the applicable regulations (CRE, 2016) require attending transient stability studies in power and distribution systems.

It is important to notice that the conventional distributed generation reduces losses, has a complete availability and can withstand with the voltage of the network through the injection of reactive power, compared to the plants based on unconventional energies, whose main limitations are incomplete availability and null reactive power delivery.

It should be noticed that the planning of the national electricity network in the short and medium-term suggests the care and availability of its generation technologies, the use and greater efficiency of the current resources available (PRODESEN, 2019).

\section{Angular transitory stability in electrical systems}

The continuity and quality of the electricity supply in medium voltage distribution systems that have distributed generation, are strongly related to studies of transient stability (Orellana, González \& Abreu, 2020).

It is always desirable for electric power supply companies and their users that the voltage and frequency parameters are always within the defined and controllable operating ranges (CRE, 2017). 
For example, maintaining an adequate plant factor without outputs due to external network failure; increases the quality, efficiency, and reliability of the network, but if unnecessary machine outputs occur, this implies a synchronization procedure that demands time and money, in addition to negatively impact on the user and the environment.

The ability of an electrical system to be synchronized when subjected to a disturbance or disbalance is called stability (Anderson \& Fouad, 2003). The disturbances may be of different kinds; such as short circuits, load losses, load connections, etc. These can be classified as large or small. Generally, small disturbances are due to a moderate variation in the load and generation of the system and, those of great magnitude normally implies the presence of short circuits, severe load-generation imbalance as well as the loss of important elements in the power grid. The behavior of an Electric Power System changes continuously and might be expressed with mathematical expressions that contain nonlinear characteristics (Kimbark, 2015).

If after a disbalance or disturbance the transient oscillatory response of an electric energy system is damped and the system reaches in a finite time to a new stable operating condition, we say that the system is stable (Kundur, 1994).

This implies that voltage and frequency oscillations must be damped to reach an acceptable operating condition. The stability of a system depends largely on the magnitude and location of the disturbance, and its operational condition before the disturbance. If stability is not maintained, the generator loses its synchronism with the network.

It is possible to analyze the transient stability of a system by formulating two sets of equations, the first one includes differential equations that describe or include the dynamics of mathematical modeling of the generators and their components such as excitation system, speed regulators and loads. The second set consists of algebraic equations that describe the behavior of the power grid to which the generator is connected (Anderson \& Fouad, 2003).
To observe the dynamic behavior of an electrical system and carry out the analysis of its transient stability, a system of equations must be solved in the way shown in equation (1). Where it represents the state of variables related to the generators and their controls (for example, rotor angle and speed, excitation voltage) and is a vector of input signals (for example, voltages and currents in different nodes of the system). This equation represents a differential simultaneous system of nonlinear equations. The solution of (1) can be done in the time domain through numerical methods techniques.

$\dot{x}=f(x, u, t)$

The method consists of solving in the time domain the oscillation equation of the system in this case represented by two first-order expressions, equations (2) and (3). For further details of the treatment and analysis of equations (1), (2) and (3) see references (Kimbark, 2015), (Anderson \& Fouad, 2003).

$\dot{\delta}=w(t)+w_{R}$

$\dot{w}=\left(\frac{w_{R}}{2 H}\right)\left(P_{m}-P_{e}(t)\right)$

By solving equations (2) and (3), the behavior of the electromechanical oscillations inherent in the system can be analyzed and the dependence of the electrical power delivered by the generator based on the angular position of its rotor can be known.

When the generator operates in a steady state, it delivers an energy (determined by a mechanical torque applied to its shaft) to the power grid with a voltage at its terminals and at a rotor speed that determines its frequency. During a short circuit, in a network where the inductive effect dominates, the balance between the mechanical torque and the electrical torque of the generator can be lost. The machine starts a gradual acceleration until the fault is isolated and its rotor accumulates kinetic energy determined by the acceleration area $\mathrm{A}_{1}$ indicated in Figure 1. The deceleration area $A_{2}$ is responsible for restoring the synchronous speed of the generator. Figure 1 shows the behavior of the real power as a function of the internal angle of the machine for the pre-fault state, during the failure and post-fault state. 


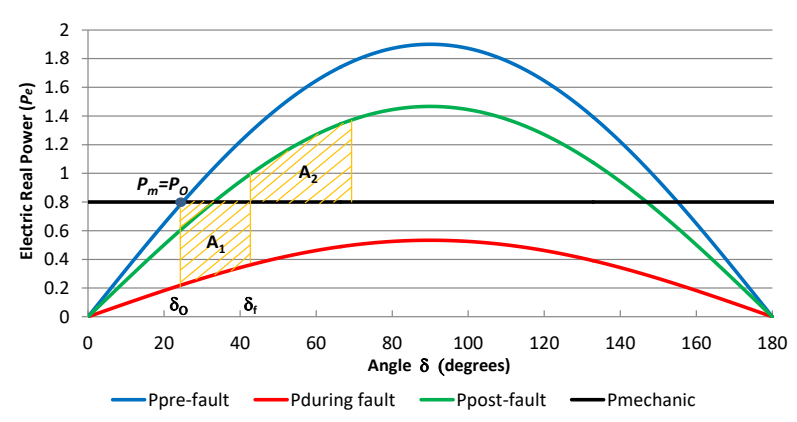

Figure 1 Power-angle feature Source: Own elaboration

In a distribution system, the post-fault curve can be very similar to the pre-fault curve since by eliminating the fault the magnitude of the Thevenin impedance at the point of the short circuit has a greater change when a transmission circuit is lost than when one of the distribution circuits is lost. Figure 1 graphically describes the criteria of equal areas for transient stability, which can be widely addressed in (Kundur, 1994).

\section{Description of the electrical network}

The Mexico City Metropolitan Zone (ZMCM), located in the Central Region of the country, demands about $24 \%$ of the energy nationwide in approximately $1 \%$ of the national territory and $70 \%$ of it comes from the eastern, western and southeast regions (PROSEDEN, 2019). The demand for electricity in the Central Region has an average annual growth rate of $2.6 \%$ (PROSEDEN, 2019), special actions have been implemented in that particular area, mainly focused on satisfying the energy supply and maintaining voltage stability. These actions include the insertion of generation, reactive power compensation and increased capacity of transformation from high to medium voltage through mobile substations (CRE, 2017).

Therefore, to reduce the generation deficit in the Central Region and the ZMCM, since 2008 a total of 15 turbogenerators distributed in the substations of Iztapalapa, Magdalena, Santa Cruz, Aragón, Coapa, Atenco, Cuautitlán, Ecatepec, Villa de las Flores, Remedios, Coyotepec (2 generators), Valle de México and Victoria are in service. Each generator has the nominal values of $40 \mathrm{MVA}$ and $13.8 \mathrm{kV}$ and natural gas is its primary source of energy.
The system discussed here corresponds to the Coapa substation located in the southern part of Mexico City. It is a medium voltage aerial distribution electrical system that feeds most of its load with the transmission network of $230 \mathrm{kV}$ through the links it has with the Topilejo and Xochimilco substations. Arrangements in 230 $\mathrm{kV}$ and $23 \mathrm{kV}$ are of the conventional type, see Figure 2 . The generator is directly connected to the $23 \mathrm{kV}$ bus $\mathrm{A}$ and is connected to the transmission network through the $\mathrm{T} 1$ power transformer. In the $23 \mathrm{kV}$ network arrangement of the substation, the link switches are kept open. That is, the power transformers are not connected in parallel. The energy provided by the turbogenerator can be consumed by loads of the distribution network of the substation and the surplus can be injected into the distribution and transmission networks.

The generator's operating policy prevents it from working when there is no link to the transmission system (it does not include the "isochronous" option). The machine speed regulation system operates in the "regulation" option when the medium voltage network is interconnected with the $230 \mathrm{kV}$ system.

Operating the turbogenerator isolated of the network is not a real problem if the load and the generation are balanced. However, when the load exceeds generation, there are stability problems that might lead to a total loss of the electricity supply (IEEE, 2008). It should be noticed that the installed capacity of the substation is $87 \%$ full and the T1 transformer handles a maximum demand of 59.9 MW. Therefore, if demand conditions and operational policies allow it, the generator could only be on the island supplying the demand for only two 23 $\mathrm{kV}$ feeders.

Also, in the case of a gas turbine generator, its main advantages are the availability and the speed of its synchronization.

\section{Analysis and simulation of the electrical network}

There are two general operating scenarios presented in this work which relate to the types of representative failures in the network and the critical points of their application, considering always the interconnection of the substation with the $230 \mathrm{kV}$ network: 
1. A fault occurs in the output conductor of a $23 \mathrm{kV}$ feeder.

2. A fault occurs in the output conductor of the $93180230 \mathrm{kV}$ circuit.

These two scenarios have been selected because they represent the most severe shortcircuit conditions that jeopardize the normal operation of the system and are located near the busbar. Also, the simulation includes the switch opening corresponding to the failed circuit.

The variables of interest in the simulations related to the generator are the rotor angle, frequency, terminal voltage, and power delivered.

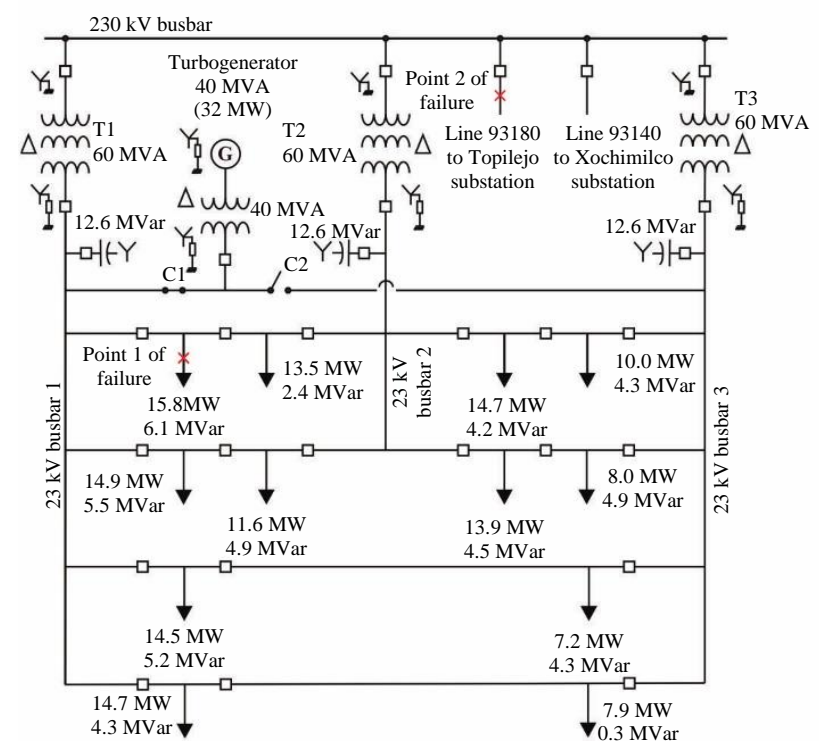

Figure 2 Simplified single-line diagram of the system under study

Figure 2 shows that the machine has the possibility of connecting to bar 1 or bar 3 through the closing of switches $\mathrm{C} 1$ or $\mathrm{C} 2$, respectively. The study considers that the machine is connected to bar 1 and provides a generation of $32 \mathrm{MW}$ to the distribution network, while the capacitor bank of bar 1 remains connected. The usual values of power generated from the Coapa substation generator are $29 \mathrm{MW}$, however, the maximum power value that can be delivered is $32 \mathrm{MW}$.

Thus, the following is obtained for the first operation scenario:

Figure 3 shows the behavior of the rotor angle during the presence and clearance of the three-phase (123F3) and single-phase (223F1) faults at point 1 .
It has been assumed that the fault occurs at the output of one of the distribution feeders, therefore when the fault is cleared, the circuit load is lost. The maximum clearing time for the three-phase fault that allows the generator to be synchronized is $131 \mathrm{~ms}$. While the release time for a single-phase fault does not affect the generator's synchronism, it is shown that even maintaining the single-phase fault for a time of $500 \mathrm{~ms}$ the system turns out to be stable. The angle of the rotor is measured concerning a reference frame that rotates synchronously.

Figure 4 shows the frequency of the generator for the single-phase and three-phase fault events shown in Figure 3. During the threephase fault, the frequency reaches a maximum value of $61.6 \mathrm{~Hz}$ and a minimum of $58.2 \mathrm{~Hz}$, the frequency has positive damping and tends to stabilization. The single-phase fault causes the machine frequency to have a dampened oscillation between 60.3 and $59.75 \mathrm{~Hz}$. The natural oscillation frequency of the electromechanical system is $3 \mathrm{~Hz}$.

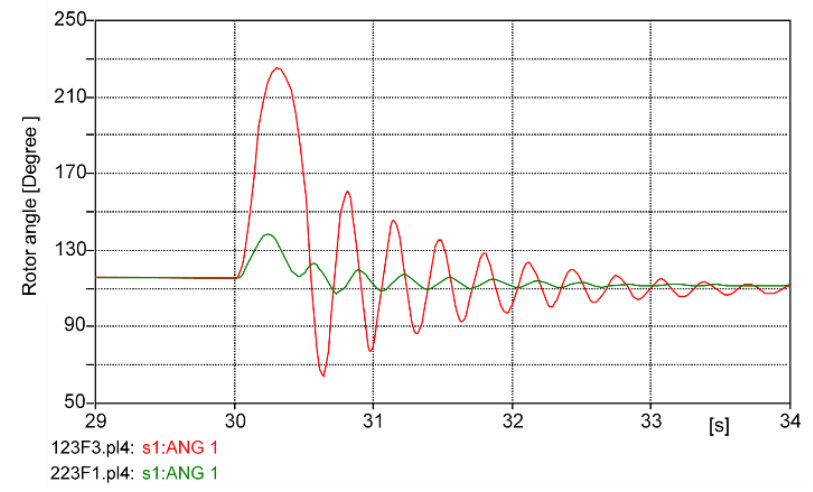

Figure 3 Rotor angle with presence and release of threephase and single-phase faults in $23 \mathrm{kV}$

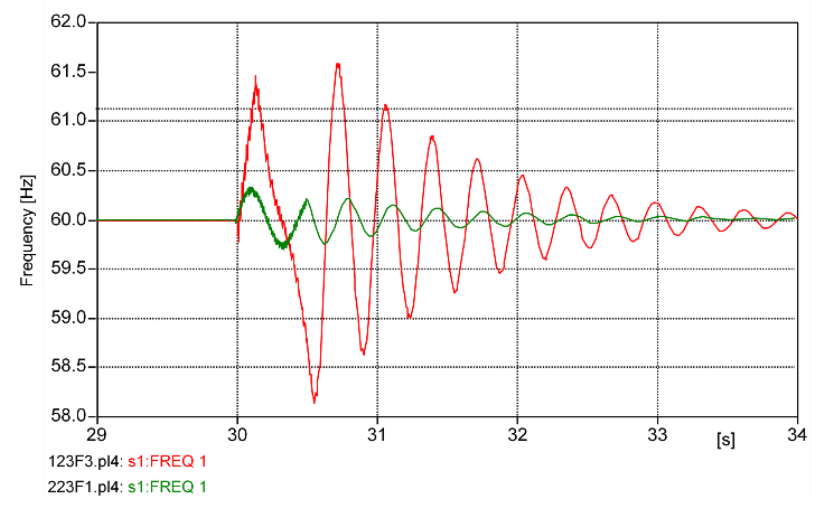

Figure 4 Frequency of the generator with presence and release of three-phase and single-phase faults in $23 \mathrm{kV}$

Figure 5 shows the apparent three-phase power output of the generator when the faults are applied at $23 \mathrm{kV}$. 
The generator contributes with 145 MVA to the three-phase fault, once the fault is cleared, positive damping reaches $110 \mathrm{MVA}$. The singlephase fault demands 68 MVA and after its release, there is also a damped oscillation.

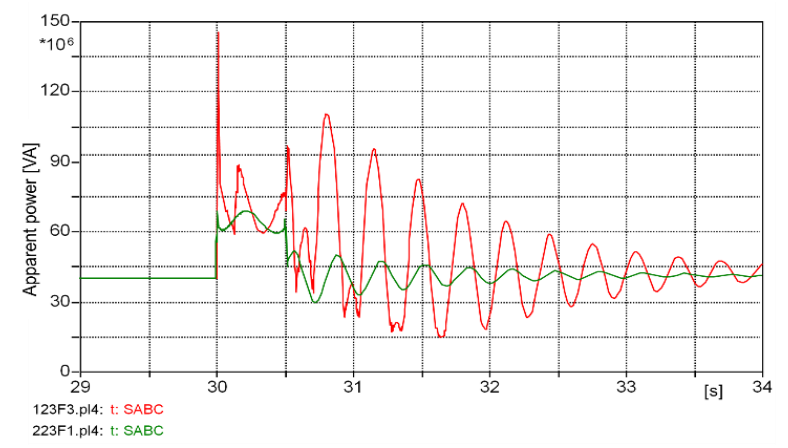

Figure 5 Generator output power due to three-phase and single-phase faults in $23 \mathrm{kV}$

The voltage behavior at the generator terminals for single-phase and three-phase faults in $23 \mathrm{kV}$ is presented in Figure 6 and 7, respectively. In the event of the three-phase fault, as shown in Figure 6, the lowest voltage depression occurs in phase $B$ with an effective phase-to-earth value of $1.8 \mathrm{kV}$. The event corresponding to the single-phase fault shows that the effectiveness phase-to-earth voltage of phase $\mathrm{A}$ is reduced to $4.7 \mathrm{kV}$, see Figure 7 . In both cases, the voltage stabilizes in approximately 4 seconds.

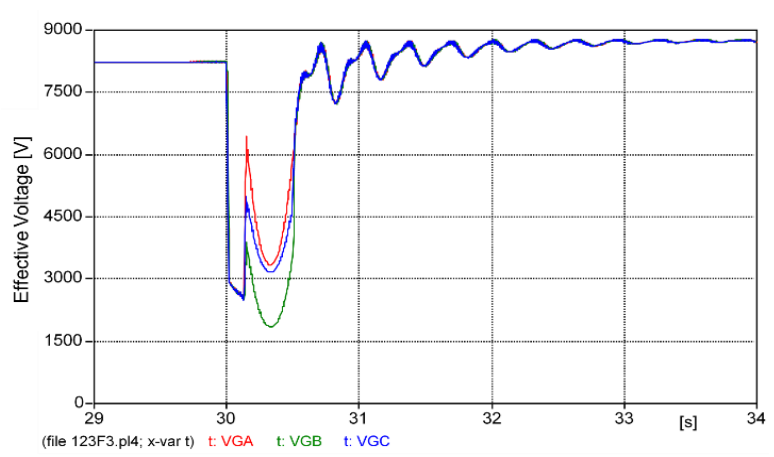

Figure 6 Behavior of the terminal voltage of the generator with presence and clearing of the three-phase faults in 23 $\mathrm{kV}$

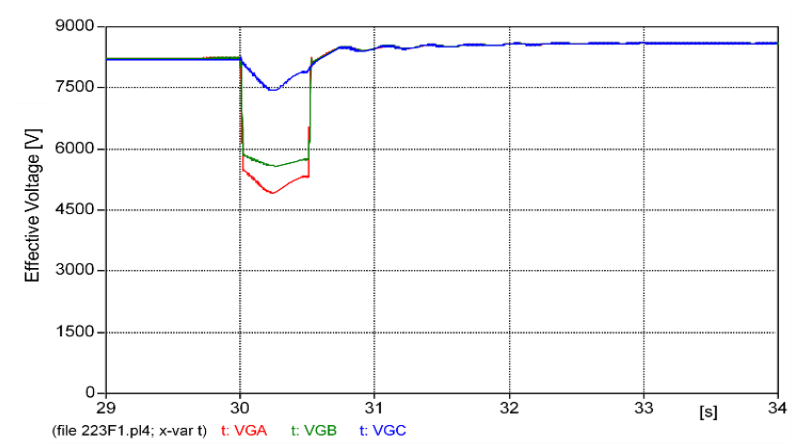

Figure 7 Behavior of the terminal voltage of the generator with presence and clearing of the single-phase faults in 23 $\mathrm{kV}$
The second scenario considers that the fault occurs in the output conductor of the 93180 $230 \mathrm{kV}$ circuit:

The maximum clearing time of the threephase fault (3230F3) that allows maintaining the synchronism of the generator is $150 \mathrm{~ms}$, while the release time of the single-phase fault $(4230 \mathrm{~F} 1)$ does not determine the stability of the system, that is, a single-phase fault can last more than $500 \mathrm{~ms}$ and still the machine will reach a steady state without losing synchronism with the network. This can be verified by observing the behavior of the rotor angle shown in Figure 8 . Although the transient stability is not lost, this relatively high fault clearing time may cause the operation of some over-current or over-voltage protection.

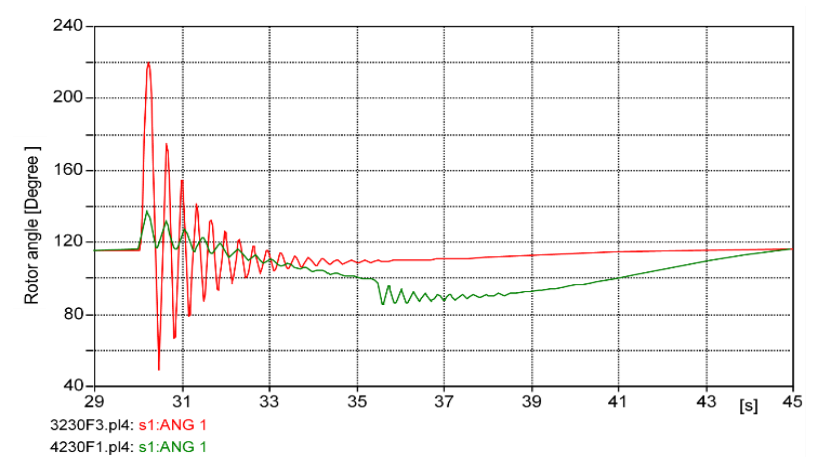

Figure 8 Rotor angle behavior with presence and clearing of three-phase faults in $23 \mathrm{kV}$

Figure 9 shows the generator frequency. The three-phase fault appears in the second 30 and is released in time $30.15 \mathrm{~s}$. If the fault clearing time is less than $150 \mathrm{~ms}$, the machine does not lose synchronism with the network.

The single-phase fault is applied in the second 30 and is cleared in the second 30.5, despite the relatively long duration of the failure the generator does not lose its synchronism with the network.

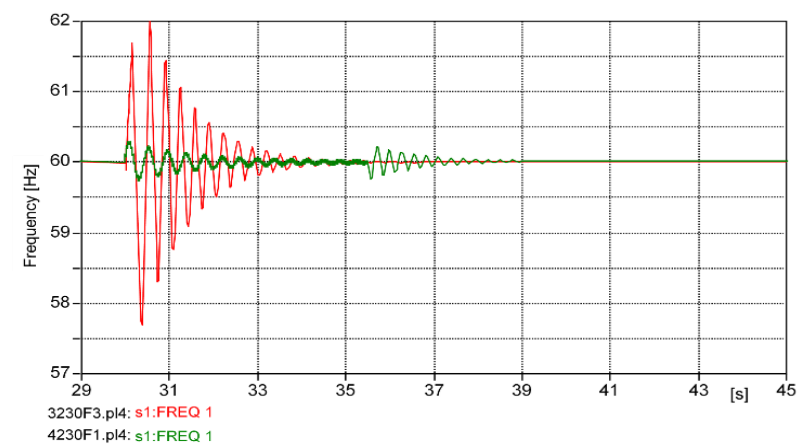

Figure 9 Frequency behavior with presence and leaning of three-phase and single-phase faults in $23 \mathrm{kV}$

CISNEROS-VILLALOBOS, Luis, VERA-DIMAS, José Gerardo, AGUILAR-MARIN, Jorge Luis and VERGARA-VÁZQUEZ, Julio Cesar. Transient angular stability on medium voltage distribution systems with distributed generation. Journal of Scientific and Technical Applications. 2021 
The apparent three-phase power output of the generator when the failures are applied at $230 \mathrm{kV}$ can be seen in Figure 10. The threephase fault is fed by 109 MVA provided by the generator, once the fault is cleared there is positive damping that reaches 115 MVA. The single-phase fault demands $56 \mathrm{MVA}$ and after its release its oscillation is damped, and its value increases gradually.

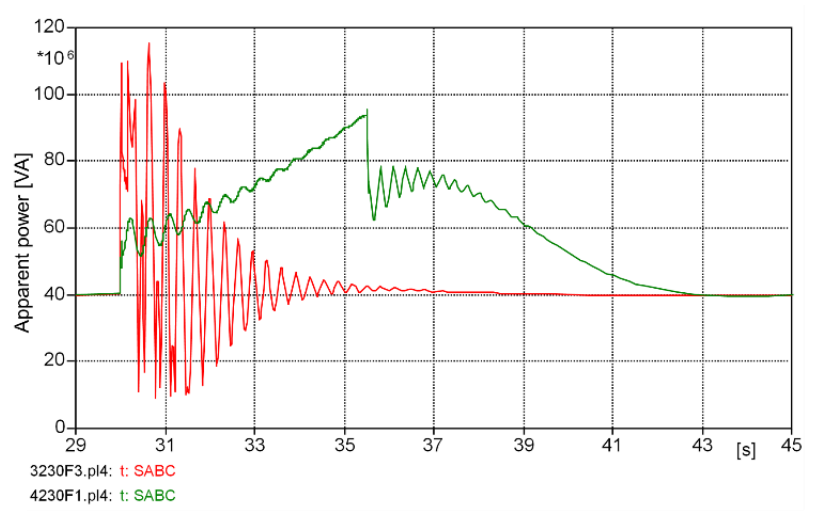

Figure 10 Generator output power due to three-phase and single-phase failures at $230 \mathrm{kV}$

Figure 11 shows the behavior of the phase voltages at the terminals of the machine before, during and after the three-phase fault, they have positive damping and reach their stable state in approximately $4 \mathrm{~s}$. During the fault, the voltage in the three phases decreases to $3.9 \mathrm{kV}$.

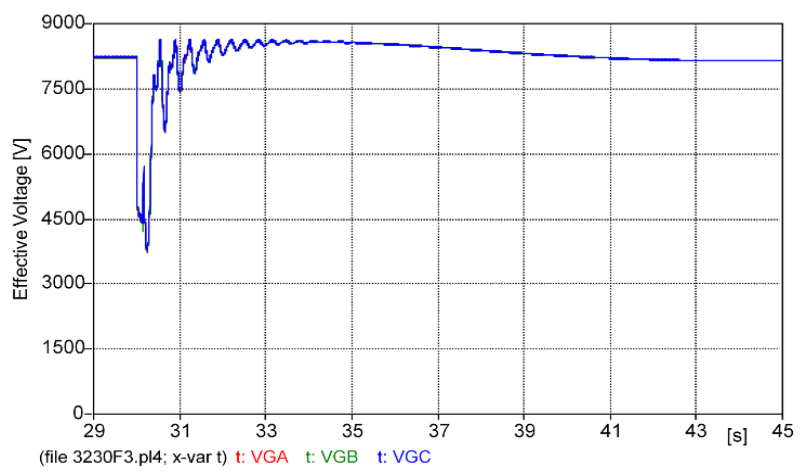

Figure 11 Behavior of the terminal voltage of the generator with presence and cleaning of the three-phase fault at $230 \mathrm{kV}$.

Figure 12 shows that $500 \mathrm{~ms}$ after the three-phase fault has been cleared, the voltage at the generator terminals tends to a steady state but, the increase in its value during the fault reaches values that are no longer operational in the power grid.

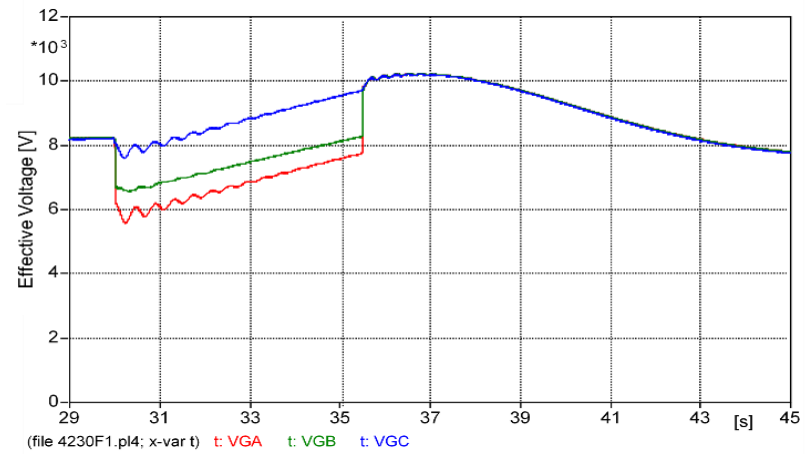

Figure 12 Behavior of the terminal voltage of the generator with presence and cleaning of the single-phase fault at $230 \mathrm{kV}$.

In Figure 13 the rotor's angle behavior and the generator frequency related to the presence and release event of the three-phase fault in $230 \mathrm{kV}$ have been plotted. The fault is cleared in a time of $160 \mathrm{~ms}$, so the system loses stability.

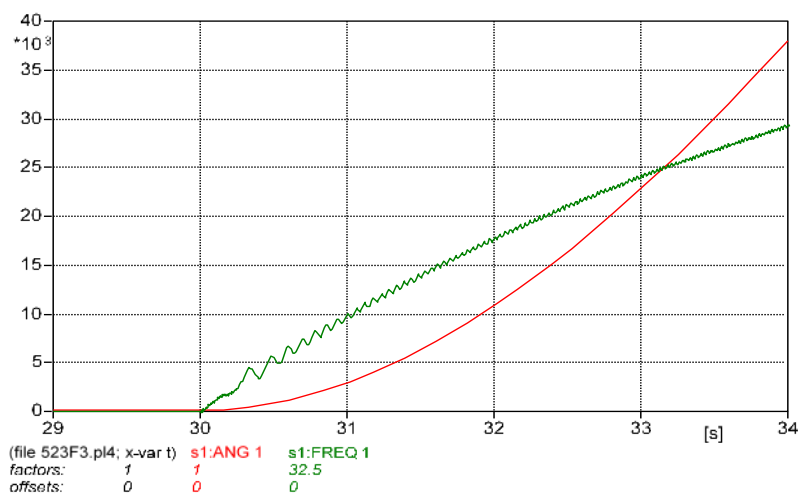

Figure 13 Rotor angle and generator frequency showing loss of stability

The results of this study are useful to define the times of adjustment of the protections of the system to improve its reliability and the correct functioning of the protection schemes which at the time did not take into account the information from a study of transient stability.

The machine does not lose stability with single-phase failures due to the magnitude of these, the neutral reactance helps to maintain stability.

\section{Conclusions}

This study always considers the link with the transmission network, so the information obtained from the scenarios presented does not have a high dependence on the electrical equivalents of the transmission and distribution networks. 
The results of the scenarios presented in this article allow us to conclude that the presence of a three-phase fault near the $23 \mathrm{kV}$ busbar of the Coapa substation with a duration greater than $131 \mathrm{~ms}$ causes the turbo generator to lose synchronism with the power grid. If the threephase fault is applied near the $230 \mathrm{kV}$ busbar and is not cleared in less than $150 \mathrm{~ms}$, the system is also unstable. The application of the singlephase fault at $23 \mathrm{kV}$ or $230 \mathrm{kV}$ does not cause the generator to lose stability, however, the voltages and currents handled by the machine in its stable state will no longer be within the permitted operating ranges. The study of transient stability performed here is unpublished and the data obtained can be used to establish design criteria and determine corrective actions at the critical time of clearing of the large number of failures that occur in the distribution system, to favor the quality and continuity of the electricity supply of the public distribution network.

\section{Acknowledgment}

The authors would like to thank the "Centro Nacional de Control de Energía and the Comisión Federal de Electricidad" for the technical support to carry out this research.

\section{References}

Anderson, P. M. and Fouad, A. A. (2003). Power System Control and Stability. Second edition, John Wiley and Sons, Inc. IEEE press.

CFE. (2017). Comisión Federal de Electricidad, Informe anual 2017.

CRE. (2016). Comisión Reguladora de Energía, Código de Red.

CRE. (2017). Comisión Reguladora de Energía, Reporte de Confiabilidad del Sistema Eléctrico Nacional 2016-2017.

Dommen, Mathew P. \& Kohler, Jeffery, L. (1995). An Improved Model for Analyzing Industrial Power Systems. IEEE Trans. On Industry Applications, 31(5):1140-1146.

Dunki, Jacobs, J. R. \& Davis, Chet, E. (1994). An Argument and Procedure for Conceptual Power System Design Studies. IEEE Trans. On Industry Applications, 30(2):253-261.
IEEE. (1997). Recommended Practice for Industrial and Commercial Power Systems Analysis. IEEE Brown Book. IEEE Std 3991997.

IEEE. (2008). Std 1547, IEEE Standard for Interconnecting Distributed Resources with Electric Power Systems.

Kundur, P. (1994). Power System Stability and Control". Mc Graw Hill.

Kimbark, E. W. (1995). Power System Stability, Volume I: Elements of Stability Calculations, USA: IEEE Press.

Orellana, U. C. González. M. L. \& Abreu. S. N. (2020). Control de un sistema de energía basado en volantes de inercia para mitigar los huecos de tensión en el punto de conexión común. Ingenius. Revista de Ciencia y Tecnología, (24), 49-58.

Paine, D. M. (2002). Increasing the Electrical Output of a Cogeneration Plant. IEEE Trans. On Industry Applications, 38(3): 726-735.

PRODESEN. (2019). Secretaría de Energía, Programa de Desarrollo del Sistema Eléctrico Nacional 2019-2033.

Rosales, S. I. López V. J. J. García P. J. Robles P. E. García A. D. \& Guzmán C. B. (2000). Interconexión de centros industriales con la red eléctrica del servicio público. Boletín IIE, pp. 42-48, enero-febrero.

Shilling, Stanley, R. (1997). Electrical Transient Stability and Under-frequency Load Shedding Analysis for a Large Pump Station. IEEE Trans. On Industry Applications, 33(1):194-201. 